Pediat. Res. 7: 575-58I (1973)

\title{
Patterns of Development of Adenyl Cyclase Activity and Norepinephrine Responsiveness in the Rat
}

\author{
Arthur F. KOHRMAN ${ }^{[26]}$ \\ Department of Human Development, College of Human Medicine, Michigan State University, \\ East Lansing, Michigan, USA
}

\begin{abstract}
Extract
The present studies were done to delineate developmental patterns of the adenyl cyclase system and its responsiveness to norepinephrine. Investigations were performed in four tissues of the rat: brain, brown fat, heart, and liver. The general developmental patterns of adenyl cyclase in brown fat, heart, and liver are similar. In all three tissues, adenyl cyclase activity reaches a nadir at approximately 14 days of age. Heart, brown fat, and liver also show similar responses to norepinephrine, which increases adenyl cyclase activity to $2-4$ times that of basal levels at all ages. The adenyl cyclase activities in the late gestational and early infant brain are relatively low compared with later ages, but are comparable to those of the other tissues in the neonatal period. Activity in cerebrum rises steadily until about 21 days of age. There is responsiveness to sodium fluoride stimulation of adenyl cyclase in all tissues examined at all ages, with values 5-20 times basal levels in brown fat, liver, and heart. In cerebrum, sodium fluoride causes stimulation of adenyl cyclase activity to about 2 times basal levels at all ages.
\end{abstract}

\section{Speculation}

Adenyl cyclase activity in brown fat in the rat is at high levels in the neonate. This may be related to the high metabolic activity and active lipolysis occurring in that tissue in the perinatal period. In the brain, adenyl cyclase activity is at very low levels in the neonate compared with the adult, rising rapidly in the 2nd and 3rd weeks of life. This pattern of development of the adenyl cyclase system in the rat brain may be related to concurrent biochemical and structural changes.

\section{Introduction}

As the multiple physiologic roles of cyclic adenosine $3^{\prime}, 5^{\prime}$-monophosphate (cAMP) unfold, an increasing body of evidence suggests that cAMP and the enzymatic systems by which it is synthesized and destroyed may have critical roles in the development of a variety of other enzymatic sequences [7, 16, 17]. Cyclic AMP is produced by the enzyme, adenyl cyclase, which catalyzes the conversion of ATP to cAMP in a magne- sium-dependent reaction. Because of the rapid, irreversible cleavage of cAMP to 5'-AMP by tissue phosphodiesterases, constant replacement is necessary for maintenance of tissue levels of cAMP. The present studies were performed: $(l)$ to outline the normal patterns of development of adenyl cyclase activity in several tissues; and (2) to begin investigation into the relation of this enzymatic system to two critical processes in the developing animal, energy metabolism and brain development. 
Cyclic AMP is required for the mobilization of both lipid and carbohydrate stores; therefore, it is extremely important in determining the availability of substrates for energy production. In the neonate these relations are particularly significant in cardiac muscle, where energy consumption is high; in brown fat, which appears to be a major locus of heat production from lipid; and in liver, where the processes of gluconeogenesis and of carbohydrate release from glycogen, both dependent on cAMP levels, are very active. Catecholamines are potent stimulators of adenyl cyclase activity, and, acting either as humoral agents or as neural transmitters at autonomic nerve endings, are thus important in control of cAMP levels in many tissues.

The highest tissue levels of adenyl cyclase activity and cAMP are found in the brain in most adult animals. Little is known, however, about the actual role of cAMP in brain development or function, or about the factors which control cAMP tissue levels in the brain of the newborn and young animal, where rapid and profound biochemical and structural changes occur during the first few days of life.

The present studies delineate developmental patterns of the adenyl cyclase system and its responsiveness to norepinephrine in four tissues of the developing rat: brain, brown fat, heart, and liver. Because adenyl cyclase is stimulated by sodium fluoride $(\mathrm{NaF})$, we have measured enzyme activity both in the presence and in the absence of $\mathrm{NaF}$ in each tissue; adenyl cyclase activity in the presence of $\mathrm{NaF}$ is assumed to indicate maximal potential activity of the enzyme.

\section{Methods}

Sprague-Dawley rats fed with Wayne Lab Blox [19] were used and maintained in a temperature-controlled environment, with 12-hour light/dark cycles. Late gestational animals were obtained by caesarian section, under ether anesthesia, on day 20 or 21 after timed matings. Older animals were killed after ether anesthesia, and tissues were then rapidly removed and transferred to ice-cold buffer.

Bitensky et al. [3] have identified sex-related differences in hepatic adenyl cyclase activity; for this reason, it would be desirable to analyze tissues from each sex separately. However, because of small quantities of tissue available from late gestational and infant animals, it was necessary to pool tissues from entire litters; therefore, tissues were taken from approximately equal numbers of male and female animals at all ages studied to maintain uniformity.
Brown adipose tissue was obtained from the interscapular area; brain tissue was taken from the anterior cerebral hemispheres; cardiac muscle was from the ventricles only.

All tissue preparation and subsequent enzyme assays were carried out in $0.05 \mathrm{M}$ Tris buffer, $\mathrm{pH} 7.4$, with or without $\mathrm{NaF}$ or norepinephrine. Tissues were homogenized gently in Kontes all glass homogenizers, then washed three times in cold buffer and centrifuged at $2,000 \times g$.

Adenyl cyclase activity was assayed by the method of Krishna et al. [9], by measurement of the conversion of ATP-8- ${ }^{-14} \mathrm{C}$ to cyclic $3^{\prime}, 5^{\prime}$-AMP-8-14 C. Final reaction mixture contained Tris $0.05 \mathrm{M}$, theophylline $0.01 \mathrm{M}$, $\mathrm{NaF}$ (where used) $0.01 \mathrm{M}$, bovine serum albumin 1 $\mathrm{mg} / \mathrm{ml}$, phosphoenolpyruvate $0.006 \mathrm{M}$, pyruvate kinase [20] $5 \mathrm{mg}, \mathrm{Mg}^{++} 0.003 \mathrm{M}$, and ATP-8-14 C $0.0005 \mathrm{~m}$ (1 $\mu \mathrm{Ci}) /$ assay tube. When required, L-norepinephrine was present at a concentration of $3 \times 10^{-5} \mathrm{M}$, a level found to cause maximum stimulation in all tissues studied. Final incubation volume was $130 \mu \mathrm{l}$; this contained $150-1,000 \mu \mathrm{g}$ of protein. Optimal protein concentration and incubation times were verified separately for each tissue at each age. The reaction was started by the addition of the substrate $\left(\mathrm{ATP}-8-{ }^{14} \mathrm{C}\right)$; the incubation was for $4 \mathrm{~min}$ at $30^{\circ}$. The reaction was stopped with the addition of carrier cAMP and immersion in a boiling water bath.

The supernatants were applied to Dowex-50 columns $(0.5$ by $3.0 \mathrm{~cm})$ and eluted with water. The first 2 $\mathrm{ml}$ were discarded and the next $3 \mathrm{ml}$ were collected for assay of labeled cAMP. The separation of labeled ATP from AMP was better than $99.95 \%$. The eluate was precipitated twice with $\mathrm{Ba}(\mathrm{OH})_{2}$ and $\mathrm{ZnSO}_{4}$ before counting in a liquid scintillation system. The measured product was verified as cAMP by column cochromatography with authentic labeled cAMP and by paper chromatography in a solvent system (1-propanol- $\mathrm{NH}_{4} \mathrm{OH}$-water; $\left.60 / 30 / 10\right)$ which widely separates cAMP from ATP, ADP, and 5'-AMP. Recoveries of cAMP were calculated for each assay tube by spectrophotometric measurement $(258 \mathrm{~m} \mu)$ in the final column eluate, and comparison with initial absorption of carrier cAMP added to tubes at the end of incubation. All data are calculated after correction to $100 \%$ recovery. Protein was assayed by the method of Lowry et al. [10].

Each determination was done in duplicate and the results are those of four to six individual experiments. It was often necessary to pool tissues from entire litters to obtain a single determination of adenyl cyclase ac- 
Table $I$. Adenyl cyclase activity

\begin{tabular}{|c|c|c|c|c|c|c|}
\hline \multirow{2}{*}{ Treatment } & \multicolumn{6}{|c|}{ Cyclic adenosine $3^{\prime}, 5^{\prime}$-monophosphate produced, $\mathrm{pmol} / \mathrm{mg}$ protein $/ \min ^{1}$} \\
\hline & -1 Day & +1 Day & 7 Days & 14 Days & 21 Days & Adult \\
\hline \multicolumn{7}{|l|}{ Brown fat } \\
\hline Control & $18 \pm 10$ & $22 \pm 6$ & $9 \pm 2$ & $10 \pm 2$ & $16 \pm 4$ & $17 \pm 3$ \\
\hline $\mathrm{NaF}$ & $243 \pm 42$ & $155 \pm 87$ & $138 \neq 15$ & $77 \pm 17$ & $107 \pm 38$ & $172 \pm 23$ \\
\hline Norepinephrine & $61 \pm 19$ & $70 \pm 6$ & $47 \pm 13$ & $40 \pm 9$ & $41 \pm 9$ & $48 \pm 15$ \\
\hline \multicolumn{7}{|l|}{ Heart } \\
\hline Control & $20 \pm 4$ & $43 \pm 10$ & $17 \pm 2$ & $16 \pm 1$ & $29 \pm .5$ & $21 \pm 3$ \\
\hline $\mathrm{NaF}$ & $174 \pm 50$ & $155 \pm 14$ & $114 \pm 23$ & $93 \pm 24$ & $148 \pm 20$ & $150 \pm 43$ \\
\hline Norepinephrine & $35 \pm 8$ & $64 \pm 12$ & $37 \pm 4$ & $31 \pm 3$ & $56 \pm 10$ & $33 \pm 8$ \\
\hline \multicolumn{7}{|l|}{ Liver } \\
\hline Control & $9 \pm 5$ & $14 \pm 5$ & $7 \pm 2$ & $4 \pm .5$ & $6 \pm .4$ & $8 \pm 2$ \\
\hline $\mathrm{NaF}$ & $120 \pm 35$ & $129 \pm 4$ & $114 \pm 37$ & $26 \pm 3$ & $78 \pm 12$ & $57 \pm 5$ \\
\hline Norepinephrine & $29 \pm 16$ & $29 \pm 9$ & $24 \pm 5$ & $12 \pm 2$ & $14 \pm 3$ & $11 \pm 3$ \\
\hline \multicolumn{7}{|l|}{ Brain } \\
\hline Control & $135 \pm 59$ & $160 \pm 7$ & $378 \pm 29$ & $578 \pm 117$ & $783 \pm 111$ & $572 \pm 9$ \\
\hline $\mathrm{NaF}$ & $300 \pm 100$ & $514 \pm 99$ & $1,007 \pm 228$ & $1,111 \pm 243$ & $1,323 \pm 193$ & $1,098 \pm 128$ \\
\hline Norepinephrine & $152 \pm 70$ & $192 \pm 28$ & $429 \pm 73$ & $622 \pm 97$ & $861 \pm 117$ & $596 \pm 37$ \\
\hline
\end{tabular}

${ }^{1}$ Mean $\pm \mathrm{SD}$.

tivity in the younger animals. Data are reported as picomoles of cyclic AMP $-8-{ }^{14} \mathrm{C}$ formed per milligram of protein per minute of incubation.

\section{Materials}

ATP-8 $-{ }^{14} \mathrm{C}$ (sp act $30 \mathrm{mCi} / \mathrm{mm}$ ) was obtained from Schwarz BioResearch Corporation [21]. Cyclic 3',5'AMP, pyruvate kinase, ATP, phosphoenolpyruvate $\left(\mathrm{Na}_{3}\right.$ salt $)$, bovine serum albumin, and L-norepinephrine were obtained from Sigma Chemical Company [22]. The resin was BioRad 50-X4 [23].

\section{Results}

Data are presented (Table I and Figs. 1-4) for animals examined at 20-21 days of gestation, at ages 1, 7, 14, and 21 days, and in early adulthood (6-10 weeks of age). The general developmental patterns of adenyl cyclase in brown fat, heart, and liver are similar (Figs. 1-3). The NaF-stimulated adenyl cyclase activity in brown fat is initially very high. In all three types of tissue, adenyl cyclase activity reaches a nadir at approximately 14 days of age, but particularly striking is the drop in responsiveness to $\mathrm{NaF}$ stimulation at that time.

The heart, brown fat, and liver also show similar responses to norepinephrine; stimulation is to $2-4$ times that of basal adenyl cyclase activity at all ages.

The developmental pattern of adenyl cyclase activity in cerebrum (Fig. 4) shows several distinctive differences from that of other tissues. The activities in the presence of $\mathrm{NaF}$ in the late gestational and early in- fant brain are relatively low, compared with those of later ages, and are at levels similar to those seen in the other tissues. Activity in cerebrum rises steadily until about 21 days of age, and then falls slightly, to the levels seen in the adult. There is essentially no response to norepinephrine stimulation in cerebrum.

There is responsiveness to NaF stimulation of adenyl cyclase in all tissues examined at all ages. In heart, liver, and brown fat, there appears to be greater relative sensitivity to $\mathrm{NaF}$ in the late gestational and newborn animals, and reduced relative sensitivity at about 14 days of age.

In cerebrum, $\mathrm{NaF}$ causes stimulation of adenyl cyclase activity to about 2 times basal levels at all ages, relatively less than in the other tissues studied, in which stimulation to 5-20 times basal levels is seen.

\section{Discussion}

Adenyl cyclase activity in the rat cerebrum rises progressively from before birth to about 3 weeks of age, and then falls slightly thereafter to the level found in the adult. There is notable NaF stimulation of adenyl cyclase activity at all ages examined. These data are in contrast to those reported by Schmidt et al. [13], who found very little adenyl cyclase activity in rat brain in the absence of $\mathrm{NaF}$ stimulation after 13 days of age. In addition, those authors reported little or no stimulation by $\mathrm{NaF}$ until after the 5th day of life. Differences in the developmental curves in the two reports may be related to the selection for our studies of a single region of the brain. There are significant regional differ- 


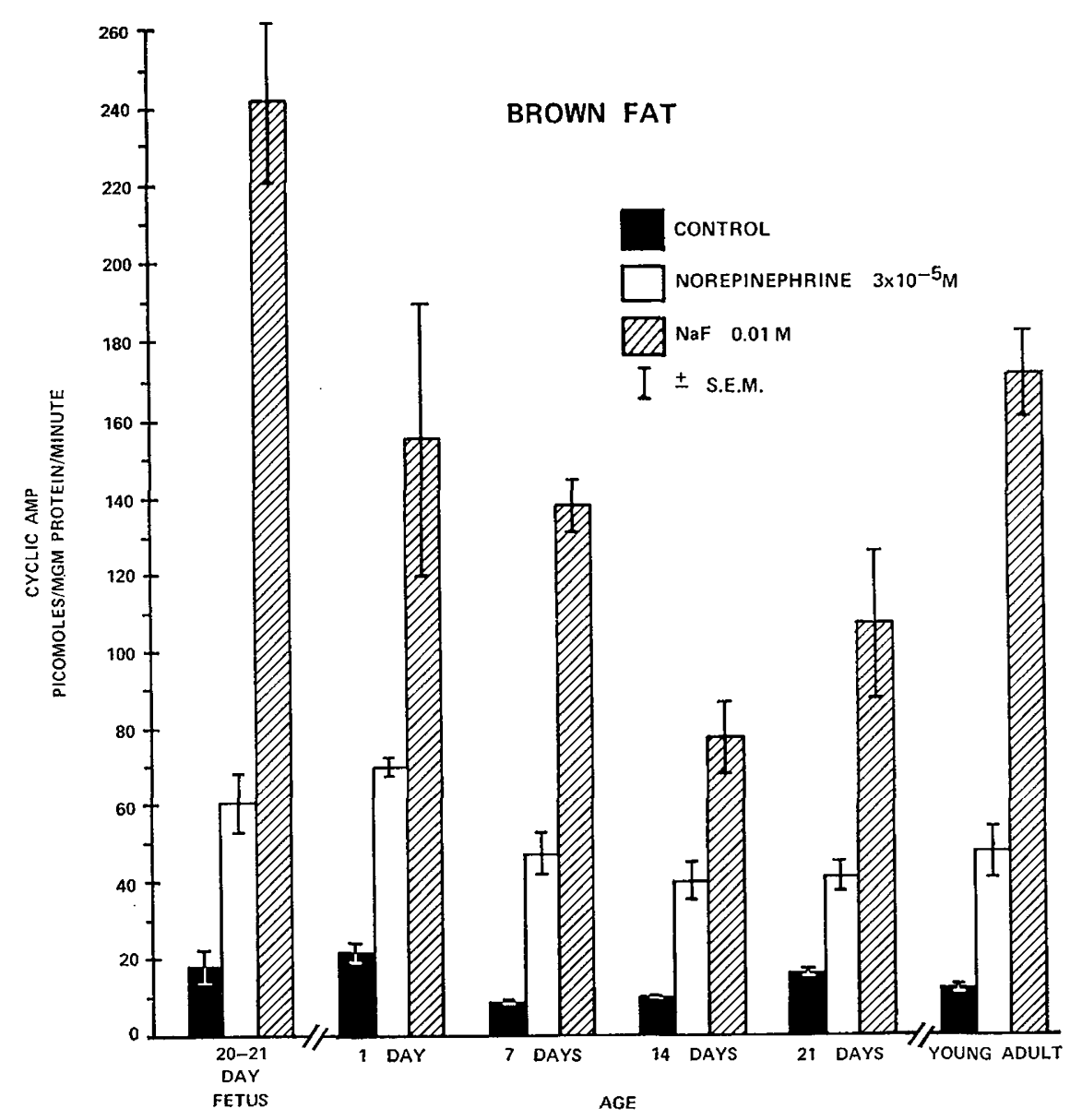

Fig. 1. Adenyl cyclase activity in brown fat from the developing rat. Cyclic AMP: Cyclic adenosine $3^{\prime}, 5^{\prime}$-monophosphate.

ences within rat brains, not only in adenyl cyclase activity but in ratios of adenyl cyclase to phosphodiesterase activity $[11,15]$. It is possible that the data of Schmidt $e t$ al. either result from developmental differences in different regions of the whole rat brain which they used, or reflect relatively slower development of adenyl cyclase activity in areas of the brain which ultimately have high phosphodiesterase levels, such as cerebellum.

The presence of significant NaF stimulation of adenyl cyclase in the cerebral cortex of 21-day fetuses and early neonates may reflect the inclusion of $\mathrm{NaF}$ at all stages of tissue homogenization and assay. In other studies it has been the practice to add $\mathrm{NaF}$ only to the final incubation buffer. The stimulation of adenyl cyclase by $\mathrm{NaF}$ in brain may have a time-dependent aspect or be in some manner related to cellular integrity; such factors might not be completely apparent in studies in which $\mathrm{NaF}$ is added after homogenization.
Although the role of the adenyl cyclase system in brain development remains uncertain, the general developmental trends seen in both unstimulated and $\mathrm{NaF}$-stimulated tissues follow the patterns of development of a variety of structural and chemical parameters in the rat. Some of these are: (l) microscopic appearance of the cerebral cortex, which very nearly achieves its adult form between the 12th and 15th postnatal day [4]; (2) total DNA content of the cerebrum, which rises rapidly between the 7 th and the 15th days and peaks at about 21 days of age [18]; (3) total brain protein, which rises rapidly between 12 and 25 days of age [1]; and (4) rates of ganglioside production and sulfatide synthesis [6]. Hommes and Beere [8] have made some similar speculations concerning the relation of development of adenyl cyclase activity in the brain to changes in cerebral electrical activity.

Our data give no suggestion of any uniform change in susceptibility of adenyl cyclase activity to $\mathrm{NaF}$ stim- 


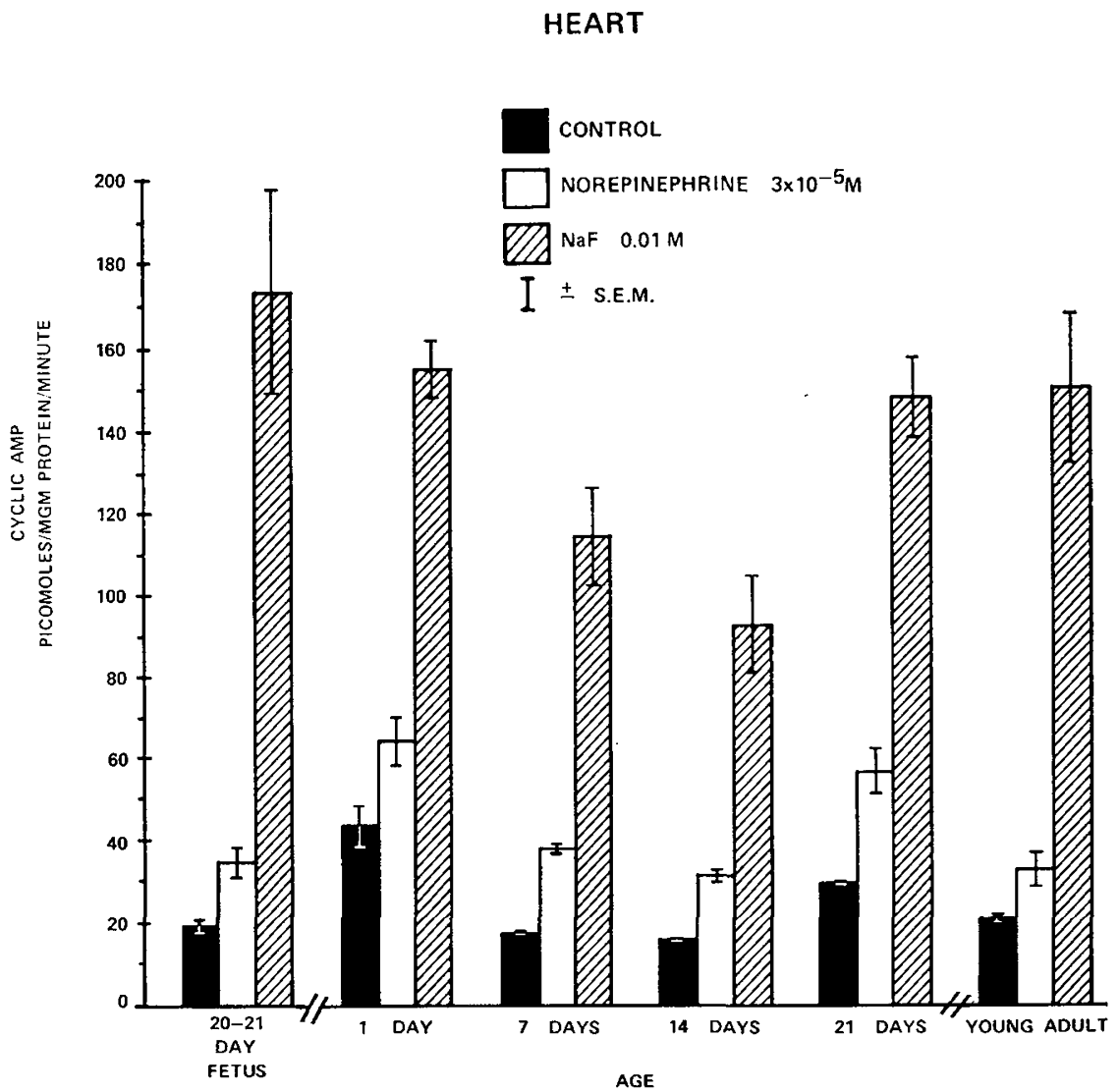

Fig. 2. Adenyl cyclase activity in cardiac tissue (ventricle) from the developing rat. Cyclic AMP: Cyclic adenosine $3^{\prime}, 5^{\prime}$-monophosphate

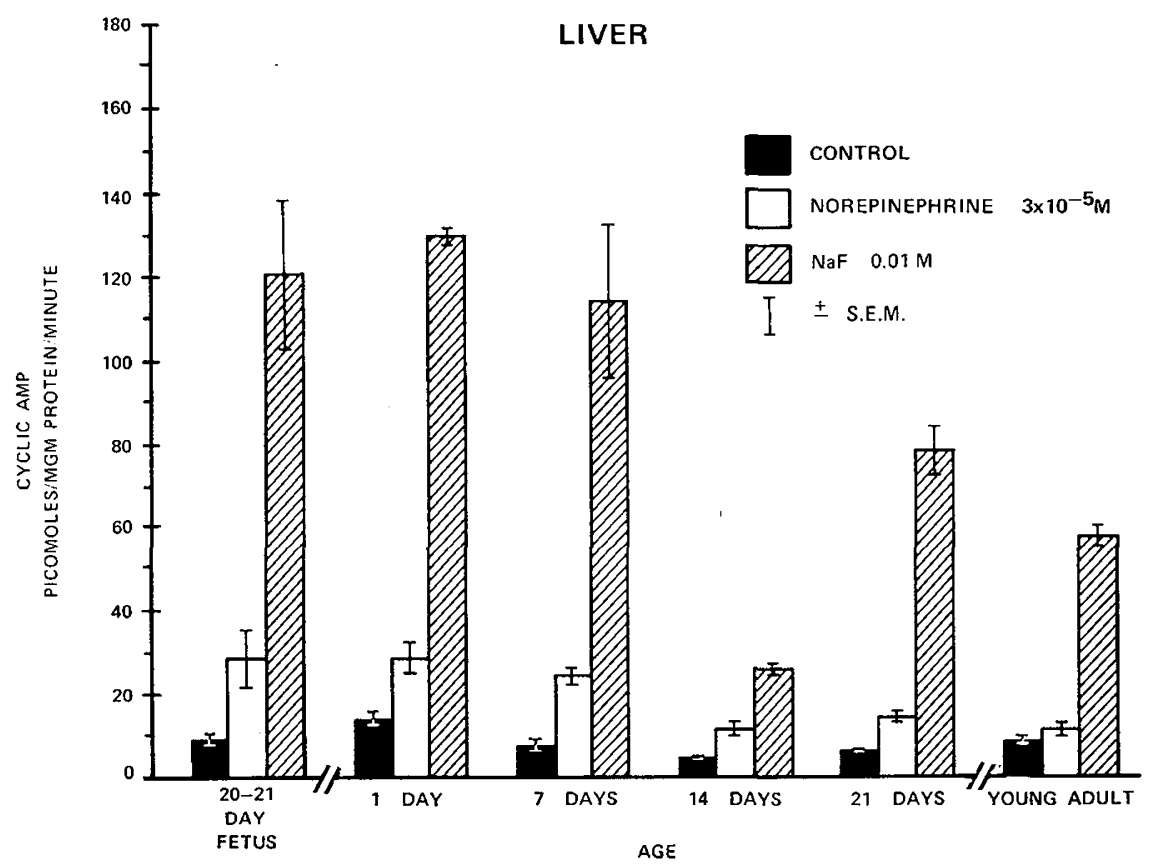

Fig. 3. Adenyl cyclase activity in liver from the developing rat. Cyclic AMP: Cyclic adenosine $3^{\prime}, 5^{\prime}$-monophosphate. 
BRAIN

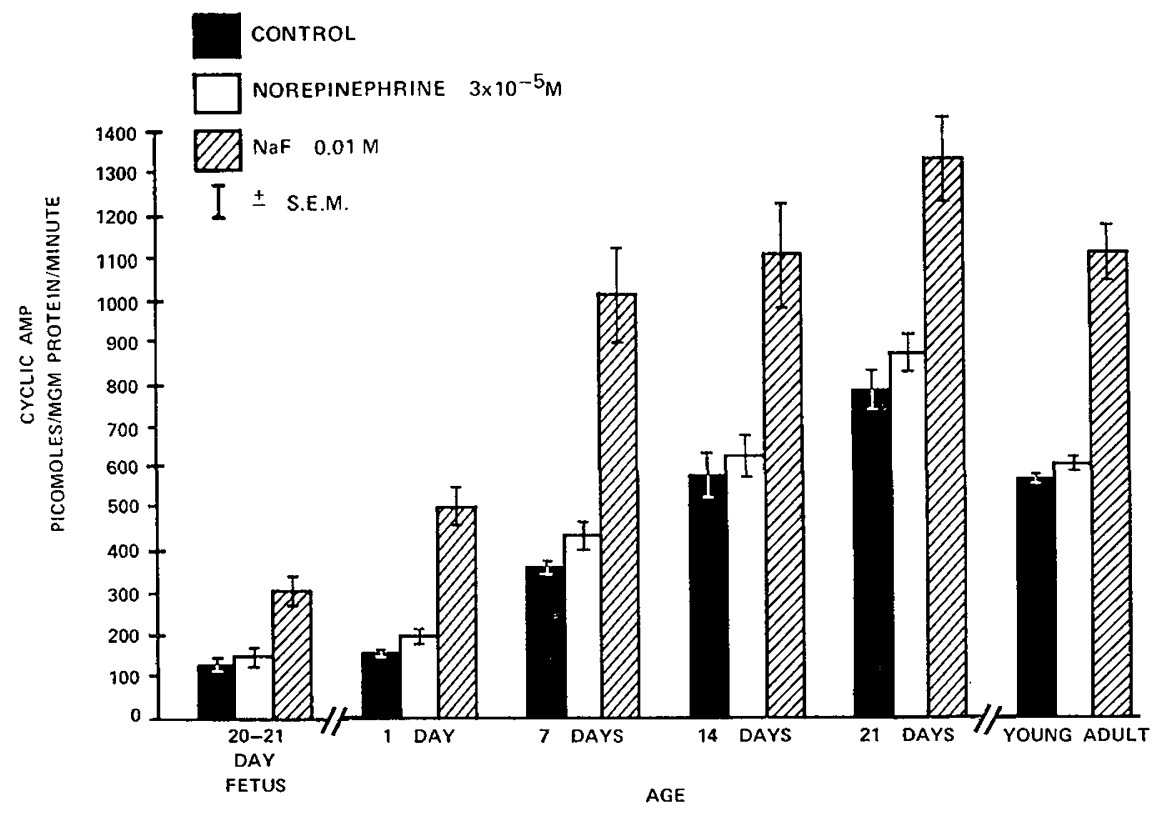

Fig. 4. Adenyl cyclase activity in brain (cerebrum) from the developing rat. Cyclic AMP: Cyclic adenosine $3^{\prime}, 5^{\prime}$-monophosphate.

ulation during development, nor is there any clue to the actual mechanism of $\mathrm{NaF}$ stimulation itself. The failure of the brain homogenate preparations to respond to norepinephrine in vitro is not unexpected. There are several reports of lack of stimulation by catecholamines of adenyl cyclase activity in crushed cell preparations of the brain; response to catecholamines does occur in brain slices or minces.

Levels of adenyl cyclase activity in brown fat are relatively high. A striking response to $\mathrm{NaF}$ is seen in brown fat, particularly in the younger animal. Basal levels of activity are of the same order of magnitude as those reported by Counis and Raulin [5] in the first 10 days of life; however, we find substantially (5-8 times) greater stimulation on addition of $\mathrm{NaF}$. Again, this discrepancy may reflect our inclusion of $\mathrm{NaF}$ from the outset of tissue preparation. Those authors did not test the effects of catecholamines on brown fat adenyl cyclase.

Although it is presumed that the significant basal levels of adenyl cyclase activity in this tissue are related to its important metabolic functions in the neonate, possibly via cAMP-stimulated lipases [14], there is no ready explanation for the large response to $\mathrm{NaF}$ stimulation, nor for the changing patterns of that response with age. The in vivo significance of $\mathrm{NaF}$ or catecholamine-stimulated adenyl cyclase activity determined in vitro is uncertain. If, in fact, the "basal" adenyl cyclase activity is that which correlates best with physiologic function, the changes noted with age in liver, brown fat, or heart are probably not significant. For this reason, we have hesitated to draw conclusions or make detailed comparison with the work of other authors concerning the findings in those tissues.

Bär and Hahn [2] have described age-related changes in hepatic adenyl cyclase activity and its responsiveness to epinephrine. Although our data for "basal" activity show the same general levels as theirs, we report markedly higher levels of activity in the presence of NaF. Possibly of greater significance, we find less change in catecholamine sensitivity with advancing age than do Bär and Hahn, although there appears to be some loss in that sensitivity in the adult liver when compared with that seen in liver from younger animals.

With the possible exception of the changes in liver sensitivity to norepinephrine in the adult rat, we find no evidence of differential responsiveness with advancing age to catecholamine stimulation of adenyl cyclase activity in liver, brown fat, or heart such as that which occurs during metamorphosis in amphibian erythrocytes [12].

\section{Summary}

The development of adenyl cyclase activity was measured in vitro in cerebrum, brown fat, liver, and heart of the rat from late gestation to adulthood. Adenyl 
cyclase activity in the cerebral cortex shows a progressive rise from birth to adult levels and a sensitivity to $\mathrm{NaF}$ stimulation at all ages examined. In brown fat, heart, and liver, basal adenyl cyclase activity levels are highest near birth. In those three types of tissue there is marked variation in sensitivity to $\mathrm{NaF}$ stimulation with age. In all three kinds of tissue there is responsiveness to norepinephrine stimulation to at least $100 \%$ above basal levels at all ages examined. However, there is no evidence of uniform differential responsiveness of adenyl cyclase to catecholamine stimulation with advancing age.

\section{References and Notes}

1. Agrawal, H. D., and Himwich, W. A.: Amino acids, proteins, and monoamines of developing brain. In: W. A. Himwich: Developmental Neurobiology, p. 287. (Charles C Thomas, Publisher, Springfield, Ill., 1970).

2. Bär, H.-P., AND HaHN, P.: Development of rat liver adenylcyclase. Can. J. Biochem., 49: 85 (1971).

3. Birenskx, M. W., Russell, V., and Blanco, M.: Independent variation of glucagon and epinephrine responsive components of hepatic adenyl cyclase as a function of age, sex and stexoid hormones. Endocrinology, 86: 154 (1970).

4. Caley, D. W.: Differentiation of the neural elements of the cerebral cortex in the rat. In: D. C. Pease: Cellular Aspects of Neural Growth and Differentiation, p. 73. (University of California Press, Los Angeles, 1971).

5. Counis, R., And Raulin, J.: Activité adénylcyclase au cours du développement foetal et néonatal du tissue adipeux brun. Bull. Soc. Chim. Biol., 52: 1393 (1972).

6. Davison, A. N.: Lipids and brain development. In: D. C. Pease: Cellular Aspects of Neural Growth and Differentiation, p. 365. (University of California Press, Los Angeles, 1971).

7. Greengard, P., and Kuo, J. F.: On the mechanism of action of cyclic AMP. In: P. Greengard and E. Costa: Role of Cyclic AMP in Cell Function: Advances in Biochemical Psychopharmacology, Vol. 3, p. 287. (Raven Press, New York, 1970).

8. Hommes, F. A., AND BeERE, A.: The development of adenyl cyclase in rat liver, kidney, brain, and skeletal muscle. Biochim. Biophys. Acta, 237: 296 (1971).

9. Krishna, G., Weiss, B., ANd Brodie, B. B.: A simple, sensitive method for the assay of adenyl cyclase. J. Pharmacol. Exp. Ther., 163: 379 (1968).

10. Lowry, O. H., Rosebrovgh, N. J., FarR, A. L., ANd Randall, R. J.: Protein measurement with the Folin phenol reagent. J. Biol. Chem., 193: 265 (195I).

11. Robison, G. A., Schmidt, M. J., And Sutherland, E. W.: On the development and properties of the brain adenyl cyclase system. In: P. Greengard and E. Costa: Role of Cyclic AMP in Cell Function. Advances in Biochemical Psychopharmacology, Vol. 3, p. 11. (Raven Press, New York, 1970).

12. Rosen, O. M., and Erlichman, J.: The development of hormone sensitivity by the adenyl cyclase of the tadpole erythrocyte. Arch. Biochem. Biophys., 133: 171 (1969).

13. Schmidt, M. J., Palmer, E. C., Dettbarn, W.-D., and Robison, G. A.: Cyclic AMP and adenyl cyclase in the developing rat brain. Developmental Psychobiol., 3: 53 (1970).

14. Skala, J., Hahn, P., and Braun, T.: Adenyl cyclase activity in brown adipose tissue of young rats. Life Sci., 9: 1201 (1970).

15. Weiss, B., AND Costa, E.: Regional and subcellular distribution of adenyl cyclase and $3^{\prime}, 5^{\prime}$ cyclic nucleotide phosphodiesterase in brain and pineal gland. Biochem. Pharmacol., 17: 2107 (1968).

16. WrCKs, W. D., KeNNEY, F. T., AND LeE, K. L.: Induction of hepatic enzyme synthesis in vivo by adenosine $3^{\prime}, 5^{\prime}$-monophosphate. J. Biol. Chem., 244: 6008 (1969).

17. Yeung, O., And Oliver, I. T.: Induction of phosphopyruvate carboxylase in neonatal rat liver by adenosine $3^{\prime}, 5^{\prime}$-cyclic monophosphate. Biochemistry, 7: 3231 (1968).

18. Zemenhof, S., and Van Marthens, E.: Hormonal and nutritional aspects of prenatal brain development. In: D. C. Pease: Cellular Aspects of Neural Growth and Differentiation, p. 329. (University of California Press, Los Angeles, 1971).

19. Allied Mills, Inc., Chicago, Ill.

20. Type II, Sigma Chemical Company, St. Louis, Mo.

21. Schwarz BioResearch Company, Orangeburg, N.Y.

22. Sigma Chemical Company, St. Louis, Mo.

23. BioRad Labs., Richmond, Calif.

24. I gratefully acknowledge the expert technical assistance of Miss Beverly Showerman.

25. This investigation was supported in part by Grant HD 03970 01 from the National Institutes of Health.

26. Requests for reprints should be addressed to: ArTHur F. Kohrman, M.D., Department of Human Development, College of Human Medicine, Michigan State University, East Lansing, Mich. 48823 (USA).

27. Accepted for publication January 24, 1973. 